\title{
Innervated Free Flap Abdominal Wall Reconstruction: A Systematic Review
}

\author{
Paul J. Therattil, MD ${ }^{1}$ Stephen L. Viviano, MD ${ }^{1} \quad$ Edward S. Lee, MD $^{1}$ Jonathan D. Keith, MD, FACS \\ ${ }^{1}$ Division of Plastic and Reconstructive Surgery, Department of \\ Surgery, Rutgers New Jersey Medical School, Newark, New Jersey \\ J Reconstr Microsurg Open 2017;2:e118-e123.

\begin{abstract}
Address for correspondence Jonathan D. Keith, MD, FACS, Division of Plastic and Reconstructive Surgery, Department of Surgery, Rutgers New Jersey Medical School, 140 Bergen Street, Suite E1620, Newark, NJ 07103 (e-mail: jdk157@njms.rutgers.edu).
\end{abstract}

\begin{abstract}
Background Reconstruction of large abdominal wall defects provides unique challenges to the plastic surgeon. Reconstruction with innervated free flaps has been described and allows for true functional replacement of "like with like." The authors sought to determine the frequency and outcomes of such reconstructions.

Methods A literature review was performed using MEDLINE (PubMed), EMBASE, and the Cochrane Collaboration Library for research articles related to innervated free flaps in abdominal wall reconstruction.

Results Nine case series (16 patients) were included who underwent free flap reconstruction of the abdominal wall with motor and/or sensory innervation. Reconstruction was performed with latissimus dorsi $(n=5)$, tensor fascia lata $(n=4)$, rectus femoris $(n=2)$, combined tensor fascia lata-anterolateral thigh $(n=2)$, combined vastus lateralis-tensor fascia lata-anterolateral thigh flaps $(n=2)$, and vastus lateralis-

\section{Keywords}

- abdominal wall reconstruction

- anterolateral thigh flap

- fasciocutaneous flap

- free flap

- innervated

- innervation

- neurotized

- neurotization

- plastic surgery

- systematic review anterolateral thigh $(n=1)$. All but one reconstruction had motor neurotization performed $(n=15)$, while only $12.5 \%(n=2)$ had sensory neurotization performed. At least $66.6 \%$ of patients $(n=10)$ who had motor neurotization regained motor function as evidenced by documented clinical examination findings while $93.3 \%$ $(n=14)$ had "satisfactory" motor function on author's subjective description of the function. Both flaps that had sensory innervation were successful with SemmesWeinstein testing of 3.61 .

Conclusion A majority of neurotized free flap reconstructions for abdominal wall defects have been performed for motor innervation, which is almost invariably successful. Sensory neurotization has been carried out for a small number of these reconstructions, and also has been successful. Improvements in techniques and outcomes in innervated free flap abdominal wall reconstruction are important to advancing efforts in abdominal wall transplantation.
\end{abstract}

Reconstruction of large full-thickness abdominal wall defects provides unique challenges to the plastic surgeon, especially when wide oncologic resection of soft tissue obviates the use of locoregional options. Defect location at the epigastrium further limits options. When abdominal wall defects are small to medium-sized, there are several options available before free flap reconstruction is needed. Component separation provides innervated muscle flaps for closing defects up to $20 \mathrm{~cm}$ (at the level of the umbilicus). ${ }^{1}$ Locoregional flaps are also available, including pedicled tensor fascia lata, anterolateral thigh, rectus femoris, and latissimus dorsi flaps. Pedicled flaps are limited, as in other regions of the body, by pedicle reach, the arc of rotation, size, unpredictable nature of the distal end of the flap, and unpredictable function of the muscle received

March 28, 2017

accepted after revision

June 22, 2017
DOI https://doi.org/

10.1055/s-0037-1606098.

ISSN 2377-0813.
Copyright (C) 2017 by Thieme Medical Publishers, Inc., 333 Seventh Avenue, New York, NY 10001, USA. Tel: +1(212) 584-4662.
License terms

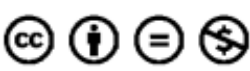


once transferred to the recipient site. It is accepted now that large, full-thickness abdominal wall defects require free flap reconstruction when they are in the midline and not amenable to component separation, or when the rectus abdominous and its fascia are not available.

Koshima et $\mathrm{al}^{2}$ described and Williams et al performed free tensor fascia lata flaps for abdominal wall reconstruction to overcome the previously described limitations of pedicled flaps. ${ }^{3}$ Since the 1980 s, the tensor fascia lata has been the flap of choice for free flap reconstruction of abdominal wall defects. ${ }^{4,5}$ Tensor fascia lata and the iliotibial band may be harvested together to reconstitute the abdominal fascia. The lateral circumflex femoral system, on which the tensor fascia lata flap is based, was found to be unique in that it allows for composite flaps, potential innervation, and enough soft tissue to reconstruction the entire abdominal wall. The anterolateral thigh, anteromedial thigh, and tensor fascia lata can be harvested together as one large flap. While we have identified excellent donor sites for free flap abdominal wall reconstruction, challenges that remain include finding ideal recipient vessels, and determining what adjunct techniques will maximize the functional outcome.

Significant advances have been made in the last 20 years with regard to the above factors, especially with the advent of innervated, or neurotized, flaps. Below, the authors review the literature on neurotized free flap abdominal wall reconstruction in an effort to clarify the available techniques, determine functional outcomes, and potentially to establish what the "gold standard" should be in free flap abdominal wall reconstruction.

\section{Methods}

MEDLINE (PubMed), EMBASE, and the Cochrane Collaboration Library were thoroughly searched by the authors from January 1975 through November 2016. Also, bibliographies of each relevant citation were reviewed for additional sources. The following search terms were used as both subjects and keywords: "abdominal wall reconstruction" AND ("neurotized" OR "neurotization" OR "functional" OR “innervated" OR “innervation”).

Two independent reviewers evaluated the titles and abstracts of all studies without language restrictions and subsequently chose studies based on the inclusion and exclusion criteria. The authors included studies that were published in scientific journals and involved patients who underwent a neurotized free flap for abdominal wall reconstruction. The authors excluded studies that were focused on procedures unrelated to neurotized free flaps for abdominal wall reconstruction, or review articles that only discussed such reconstructions without reporting on any specific cases. Discrepancies between the reviewers were discussed, and a third senior author (J.D.K.) decided as to whether the study should be included or excluded. The references of each study were reviewed for additional potential studies. The full text of studies that met criteria was reviewed as a second stage, and additional exclusions were made. Techniques involving neurotized free flap reconstruction of abdominal wall de-

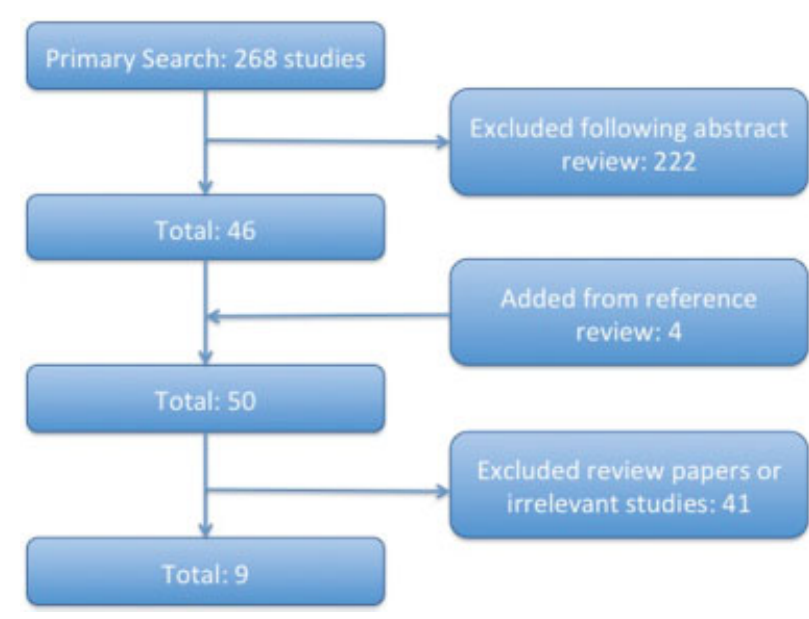

Fig. 1 Article search process and results totaling nine articles.

fects were evaluated and compared, as were the motor, sensory, and functional outcomes related to flap transfer.

\section{Results}

The initial PubMed search yielded 264 studies. The Cochrane database search yielded four studies. After reviewing the abstracts based on our criteria, 46 studies were selected pertaining to abdominal wall reconstruction with free flaps. Additional review of references of these articles yielded four more articles. After reviewing the full text of studies and making final exclusions, the final pool of studies pertaining to neurotized free flap reconstruction of the abdominal wall was comprised of nine case series with a total of 16 patients (-Fig. $\mathbf{1}$ ).

The mean age of patients in these series was 40.4 years old (range: 17-71). Eight of the patients were males (50.0\%), 6 were females (37.5\%), and 2 were unknown (12.5\%). Locally aggressive soft tissue masses were the etiology for $37.5 \%$ of defects $(n=6)$, incisional hernia for $31.3 \%(n=5)$, motor vehicle trauma for $18.8 \%(n=3)$, and recurrent or metastatic oncologic disease for $12.5 \%(n=2)$. The mean defect size requiring free flap abdominal wall reconstruction was $392.2 \mathrm{~cm}^{2}$ (range: $180-700$ ) (-Table 1 ).

Average time to surgery after the initial indication was 24 months (range: $0-144$ ). The latissimus dorsi was used in $31.3 \%$ of reconstructions $(n=5)$, tensor fascia lata in $25 \%$ $(n=4)$, rectus femoris in $12.5 \%(n=2)$, combined tensor fascia lata-anterolateral thigh in $12.5 \%(n=2)$, combined vastus lateralis-tensor fascia lata-anterolateral thigh flaps in $12.5 \%(n=2)$, and vastus lateralis-anterolateral thigh in $6.3 \%$ $(n=1)$. The recipient vessel was the inferior epigastric in $50 \%$ of reconstructions $(n=8)$, gastroepiploic in $12.5 \%$ $(n=2)$, femoral in $12.5 \%(n=2)$, lateral femoral circumflex in $6.3 \%(n=1)$, superficial epigastric in $6.3 \%(n=1)$, and unknown in $12.5 \%(n=2)$. Mesh was utilized in $25 \%$ of reconstructions ( $n=4)$-three synthetic and one biological mesh. Osseous fixation of the flap was performed in $25 \%$ of reconstructions $(n=4)$ (-Table 2 ).

All but one reconstruction had motor neurotization performed $(n=15)$, while only $12.5 \%(n=2)$ had sensory 
Table 1 Preoperative data including study type, age, and etiology

\begin{tabular}{|l|l|l|l|l|}
\hline Reference & Type of study & $\begin{array}{l}\text { No. of } \\
\text { patients }\end{array}$ & $\begin{array}{l}\text { Average age } \\
\text { (range) (y) }\end{array}$ & Etiology of defect \\
\hline Ninković et al (1998) & Retrospective & 4 & $23(17-29)$ & MVA, dermatofibrosarcoma protuberans, sarcoma (2) \\
\hline Sasaki et al (1998) & Retrospective & 2 & $47.5(27-68)$ & $\begin{array}{l}\text { Squamous cell carcinoma in fistula, ovarian cancer } \\
\text { metastases to abdomen }\end{array}$ \\
\hline Koshima et al (1999) $)^{21}$ & Retrospective & 1 & 71 & Incisional hernia \\
\hline Koshima et al (2003) & Retrospective & 1 & 48 & Sigmoid colon rupture \\
\hline Malheiro et al (2007) & Retrospective & 1 & 38 & Complicated perforated gastric ulcer \\
\hline Wong et al (2009) & Retrospective & 2 & $47.5(41-54)$ & Incisional hernia status-postnephrectomy, blunt trauma \\
\hline Chalfoun et al (2012) & Retrospective & 2 & $29(23-35)$ & Motorcycle crash (2) \\
\hline lida et al (2013) & Retrospective & 2 & $44(43-45)$ & Dermatofibrosarcoma protuberans (2) \\
\hline Hahn et al (2016) & Retrospective & 1 & 26 & Recurrent desmoid tumor \\
\hline
\end{tabular}

Abbreviation: MVA, motor vehicle accident.

Table 2 Intraoperative data including defect size, flap type, neurotization type, neurroraphy, recipient vessels, surgical delay, mesh use, and osseous fixation

\begin{tabular}{|c|c|c|c|c|c|c|c|c|}
\hline Reference & $\begin{array}{l}\text { Defect } \\
\left(\mathrm{cm}^{2}\right)\end{array}$ & Flap & Neurotization & $\begin{array}{l}\text { Nerve } \\
\text { recipient }\end{array}$ & Recipient vessel & $\begin{array}{l}\text { Average } \\
\text { surgical delay } \\
\text { (range) (mo) }\end{array}$ & Mesh & $\begin{array}{l}\text { Osseous } \\
\text { fixation }\end{array}$ \\
\hline $\begin{array}{l}\text { Ninković et al } \\
\text { (1998) }\end{array}$ & $\begin{array}{l}\text { 700, 364, } \\
\text { unknown } \\
\text { (2) }\end{array}$ & $\begin{array}{l}\text { Latissimus } \\
\text { dorsi (4) }\end{array}$ & Motor (4) & Intercostal (4) & $\begin{array}{l}\text { Superior epigastric (1), } \\
\text { inferior epigastric (1), } \\
\text { unknown (2) }\end{array}$ & $78(12-144)$ & $\begin{array}{l}\text { Synthetic } \\
\text { (2), none } \\
\text { (2) }\end{array}$ & None \\
\hline $\begin{array}{l}\text { Sasaki et al } \\
\text { (1998) }\end{array}$ & 396,204 & $\begin{array}{l}\text { Tensor fascia } \\
\text { lata (1), } \\
\text { ALT (2) }\end{array}$ & Motor (2) & Intercostal (2) & Inferior epigastric (2) & $6(0-12)$ & None (2) & None \\
\hline $\begin{array}{l}\text { Koshima et al } \\
\text { (1999) }\end{array}$ & 180 & Rectus femoris & Motor & T10 intercostal & $\begin{array}{l}\text { Lateral femoral } \\
\text { circumflex }\end{array}$ & 24 & None & Yes \\
\hline $\begin{array}{l}\text { Koshima et al } \\
\text { (2003) }\end{array}$ & Unknown & Rectus femoris & Motor & $\begin{array}{l}\text { Femoral nerve } \\
\text { branch left } \\
\text { intact }\end{array}$ & Gastroepiploic & 36 & None & Yes \\
\hline $\begin{array}{l}\text { Malheiro et al } \\
\text { (2007) }\end{array}$ & 500 & $\begin{array}{l}\text { Latissimus } \\
\text { dorsi }\end{array}$ & Motor & Intercostal & Inferior epigastric & 12 & Synthetic & None \\
\hline $\begin{array}{l}\text { Wong et al } \\
\text { (2009) }\end{array}$ & 375,525 & $\begin{array}{l}\text { Tensor fascia } \\
\text { lata (2) }\end{array}$ & Motor (2) & $\begin{array}{l}\text { T10 intercostal } \\
\text { (1), unknown } \\
\text { (1) }\end{array}$ & Femoral artery (2) & Unknown & None (2) & None (2) \\
\hline $\begin{array}{l}\text { Chalfoun et al } \\
\text { (2012) }\end{array}$ & 360,700 & $\begin{array}{l}\text { Tensor fascia } \\
\text { lata (2) }\end{array}$ & Motor (2) & Intercostal (2) & Inferior epigastric (2) & Unknown & None (2) & Yes (2) \\
\hline $\begin{array}{l}\text { lida et al } \\
\text { (2013) }\end{array}$ & 224,195 & $\begin{array}{l}\text { Vastus lateralis/ } \\
\text { tensor fascia } \\
\text { lata/ALT (2) }\end{array}$ & $\begin{array}{l}\text { Motor (1), } \\
\text { motor and } \\
\text { sensory (1) }\end{array}$ & $\begin{array}{l}\text { T7 intercostal } \\
\text { (1), T10 } \\
\text { intercostal } \\
\text { (1) }\end{array}$ & Inferior epigastric (2) & 0 & None (2) & None (2) \\
\hline $\begin{array}{l}\text { Hahn et al } \\
\text { (2016) }\end{array}$ & 375 & $\begin{array}{l}\text { Vastus lateralis/ } \\
\text { ALT }\end{array}$ & Sensory & T5 intercostal & Gastroepiploic & 0 & Biologic & None \\
\hline
\end{tabular}

Abbreviation: ALT, anterolateral thigh.

neurotization performed. One reconstruction had both motor and sensory innervation. Neurroraphy was performed to an intercostal nerve in $87.5 \%$ of cases $(n=14)$, and unknown in $6.3 \%(n=1)$. The femoral nerve was left intact in one case for motor innervation of a rectus femoris flap. At least $66.6 \%$ of patients $(n=10)$ who had motor neurotization regained motor function as evidenced by voluntary contraction, hip flexion, or the ability to sit up, while $93.3 \%(n=14)$ had "satisfactory" motor function on author's subjective description (one patient died from metastases before follow-up). Electromyography was used to confirm innervation in $37.5 \%$ of patients $(n=6)$. Both flaps that had sensory innervation were successful with Semmes-Weinstein testing of 3.61. Average patient follow-up was 25.4 months (range: 1.5-60) (-Tables 2 and 3).

Major complications occurred in $18.8 \%$ of patients during the acute recovery period (venous thrombosis of flap [ $n=2]$, died from metastasis $[n=1])$. Flap survival was $100 \%$ ( $n=16$ ), including two flaps requiring a return to the operating room for evacuation of venous thrombosis and vein grafting. Minor complications occurred in $12.5 \%$ of patients (seroma, $n=2$ ). No patients had developed hernias during the follow-up period ( - Table 3 ). 
Table 3 Postoperative data including follow-up, functional recovery, sensation, complications, reoperation, and flap survival

\begin{tabular}{|c|c|c|c|c|c|c|c|}
\hline Reference & $\begin{array}{l}\text { Average } \\
\text { follow-up } \\
\text { (range) (mo) }\end{array}$ & $\begin{array}{l}\text { Clinical } \\
\text { functional } \\
\text { recovery }\end{array}$ & $\begin{array}{l}\text { Sensation } \\
\text { (Semmes- } \\
\text { Weinstein } \\
\text { test) }\end{array}$ & Major complications & $\begin{array}{l}\text { Minor } \\
\text { complications }\end{array}$ & Reoperation & Flap survival \\
\hline Ninković et al (1998) & $88(2-37)$ & $\begin{array}{l}75 \% \\
\text { (Unknown (1)) }\end{array}$ & $\mathrm{N} / \mathrm{A}$ & $\begin{array}{l}50 \% \text { (Flap venous } \\
\text { thrombosis [1], } \\
\text { died from } \\
\text { metastases [1]) }\end{array}$ & $\begin{array}{l}25 \% \\
\text { (seroma [1]) }\end{array}$ & $\begin{array}{l}25 \% \\
\text { (saphenous vein } \\
\text { graft to inferior } \\
\text { epigastric [1]) }\end{array}$ & $100 \%$ \\
\hline Sasaki et al (1998) & $30.7(1.5-60)$ & $\begin{array}{l}50 \% \\
\text { (Unknown [1]) }\end{array}$ & $\mathrm{N} / \mathrm{A}$ & $0 \%$ & $0 \%$ & $0 \%$ & $100 \%$ \\
\hline Koshima et al (1999) & 54 & Unknown & $\mathrm{N} / \mathrm{A}$ & $0 \%$ & $0 \%$ & $0 \%$ & $100 \%$ \\
\hline Koshima et al (2003) & 54 & $100 \%$ & $\mathrm{~N} / \mathrm{A}$ & $0 \%$ & $0 \%$ & $0 \%$ & $100 \%$ \\
\hline Malheiro et al (2007) & 24 & Unknown & $\mathrm{N} / \mathrm{A}$ & $0 \%$ & $0 \%$ & $0 \%$ & $100 \%$ \\
\hline Wong et al (2009) & $\begin{array}{l}\text { 12, } \\
\text { unknown (1) }\end{array}$ & $\begin{array}{l}50 \% \\
\text { (Unknown (1)) }\end{array}$ & $\mathrm{N} / \mathrm{A}$ & $0 \%$ & $0 \%$ & $0 \%$ & $100 \%$ \\
\hline Chalfoun et al (2012) & $\begin{array}{l}\text { 10, } \\
\text { unknown (1) }\end{array}$ & $100 \%$ & $\mathrm{~N} / \mathrm{A}$ & $\begin{array}{l}50 \% \text { (flap venous } \\
\text { thrombosis [1]) }\end{array}$ & $0 \%$ & $\begin{array}{l}50 \% \\
\text { (lateral femoral } \\
\text { circumflex vein } \\
\text { graft [1]) }\end{array}$ & $100 \%$ \\
\hline lida et al (2013) & $17(10-24)$ & $100 \%$ & $\begin{array}{l}3.61(1) \\
\text { N/A (1) }\end{array}$ & $0 \%$ & $0 \%$ & $0 \%$ & $100 \%$ \\
\hline Hahn et al (2016) & 18 & $\mathrm{~N} / \mathrm{A}$ & 3.61 & $0 \%$ & $\begin{array}{l}100 \% \\
(\text { Seroma (1)) }\end{array}$ & $0 \%$ & $100 \%$ \\
\hline
\end{tabular}

\section{Discussion}

Despite the relative complexity of the cases in this review, abdominal wall reconstruction with neurotized free flaps appears to be a safe procedure with a high rate of success. There were no free flap losses in any of the case series, and the two cases requiring a return to the operating room for venous thrombosis were salvaged with vein grafts. The other associated complications were seromas that were managed successfully with percutaneous drainage. With regard to functionality, motor innervation of free flaps appears to be successful in over $93 \%$ of cases and sensory innervation in $100 \%$ of cases. Although functionality was often measured subjectively, or on physical examination, motor innervation was additionally confirmed with electromyogram in over onethird of cases. Although longer term data are needed, none of these patients have developed hernias during an average follow-up period of more than 2 years. Although this is a small set of patients, it is clear that neurotized free flaps have great potential to restore long-term function to the abdominal wall. However, there are many considerations when designing free flaps for abdominal wall reconstruction for which we do not have a "gold standard": flap type, recipient vessel, mesh use, osseous fixation, and motor and/or sensory innervation. Below the authors discuss some of these considerations and lessons learned from this systematic review.

\section{Recipient Vessels}

Potential abdominal wall recipient vessels include the superior and inferior epigastric, intercostal, superficial circumflex iliac, and gastroepiploic vessels. More distant recipients who have been used in thoracic and abdominal wall reconstruction include the thoracoacromial, thoracodorsal, and cervical vessels. $^{6}$
When there is large tumor expiration of the abdominal wall, several of these options may be precluded. Also, use of extraperitoneal vessels will restrict the type of flap that can be used. Flaps with a short pedicle, or those with a pedicle located at the center of the flap, will not be able to be used when the recipient's vessels sit at the periphery of the abdominal wound. Use of peripheral recipient vessels may also result in kinking of the pedicle and subsequent venous thrombosis, which occurred in multiple cases. ${ }^{5-7}$ None of the flaps in these series that were anastomosed to the gastroepiploic vessels had complications. The gastroepiploic vessels are likely the most versatile, and often overlooked, recipient for free flap abdominal wall reconstruction. ${ }^{8}$ The vessels are simple to locate when the peritoneum is open-they can be found just inferior to the pylorus, parallel to the greater curvature of the stomach. The gastroepiploic vessels can be dissected out to a length of around $10 \mathrm{~cm}$ with a diameter in the range of 2 to $3 \mathrm{~mm} .^{8,9}$ Also, if the pedicle is at the deep surface of the flap, an uninterrupted fascial closure can be performed without having to leave an open passage for the pedicle, as would be necessary when using extraperitoneal vessels. ${ }^{6}$ When a mesh underlay is used to reconstitute the fascial layer, a "window" at an intercostal space can be made for the pedicle to run through. ${ }^{10}$ This allows for uninterrupted mesh closure of the fascial layer, as well as prevention of pedicle kinking if the pedicle had been run around the edge of the mesh (-Fig. 2 ).

There are situations in which all abdominal vessels have been damaged and thus are not available (i.e., scarring and fibrosis from prior surgeries). One possibility is to create an arteriovenous shunt, or Corlett's loop, between the femoral artery and the long saphenous vein. The arteriovenous loop can then be rotated superiorly toward the abdominal defect and divided to provide arterial inflow and venous outflow. ${ }^{11}$ 


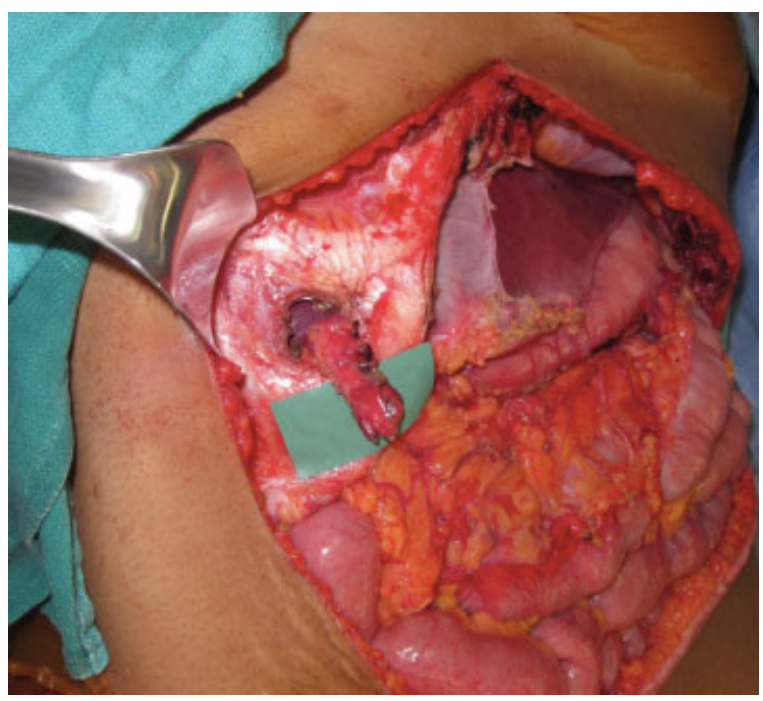

Fig. 2 The gastroepiploic vessels can be tunneled through a window in an intercostal space when utilizing an underlay mesh closure.

\section{Neurotized Flaps}

Reconstruction of full-thickness defects of the abdominal wall is unique in that while the integrity of musculofascial layer may be restored, dynamic stability is not always returned. The importance of the stability provided by the rectus abdominous muscles is demonstrated by the reduced abdominal flexion and rotational strength, pain, hernias, and bulges that result after transverse rectus abdominis flap transfer and the secondary displacement of the oblique muscles. ${ }^{12}$ Innervated, or neurotized, flaps allow for the potential passive tone of the abdominal wall, prevention of flap atrophy, and even active muscle contraction. If flap atrophy occurs, as with a noninnervated flap, abdominal wall laxity may result. ${ }^{13}$ Therefore, a majority of large abdominal wall reconstruction being performed, either with acellular dermal matrix and fasciocutaneous free flaps or with noninnervated musculocutaneous flaps, have the same potential consequences-an abdominal wall that lacks dynamic strength and may result in chronic pain and weakness for the patient.

Neurotized tensor fascia lata, rectus femoris, and latissimus dorsi flaps have been used to provide dynamic stability of the lower abdominal wall successfully. ${ }^{5,13}$ Neurotized composite flaps of the anterolateral thigh have also been described as having success using the vastus lateralis as the muscle component with its femoral nerve branch for neurroraphy. ${ }^{14}$ There is still, however, the debate as to the optimal method in performing neurotized free flap abdominal wall reconstruction. The results with neurotized, or reinnervated, free muscle flaps for abdominal wall reconstruction have been questioned by some who feel that the best possible outcome occurs by performing a free flap, but leaving the motor nerve intact. ${ }^{13}$ This would obviously require a very tedious dissection. The technical details of flap inset and fixation are also critical. Some surgeons argue that innervated flaps for abdominal wall reconstruction are not useful when sutured to the fascial edges of the defect alone, as this is not a stable point of fixation. Bony stabilization of one end of the flap to the pelvic ring has been performed and may be helpful in maintaining dynamic stability. Cases using osseous fixation are lacking, but have proven successful in one small series of patients. ${ }^{5}$

When considering the optimal abdominal wall reconstruction, skin, and fascial continuity would be restored, the musculofascial component would remain innervated with the ability for contraction, and the skin component would be sensate. While this is the theoretical ideal, we are rarely able to achieve this level of reconstruction. While nine case series exist describing free flaps for innervated abdominal wall reconstruction, it can be seen from the above systematic review that few describe successful sensory reinnervation. ${ }^{10,14}$ Iida et al described using a free combined vastus lateralis and anterolateral thigh flap for abdominal wall reconstruction in which the both the sensory and motor components were neurotized. The femoral nerve to the vastus lateralis and the lateral femoral cutaneous nerve were anastomosed to the intercostal nerve. Electromyography confirmed contraction of the vastus lateralis component while SemmesWeinstein testing confirmed sensation. ${ }^{14} \mathrm{Hahn}$ et al reported a second case of successful sensory innervation of a free combined vastus lateralis and anterolateral thigh flap for abdominal wall reconstruction. ${ }^{10}$

\section{Applications to Composite Tissue Allotransplantation of the Abdominal Wall}

The concepts critical to functional free flap abdominal wall reconstruction are also applicable to composite tissue allotransplantation of the abdominal wall. While abdominal wall transplantation has been performed successfully in patients undergoing concurrent solid organ transplantation, it has come across several challenges including poor functional outcomes and controversy with regard to the optimal anatomic configuration of the allograft. ${ }^{15}$ These problems have limited the applicability of elective abdominal wall transplants in patients not requiring solid organ transplantation. The lack of innervation and lack of bony stability of these allografts have been flagged as potential causes for poor functionality with a resultant hernia and bulge. ${ }^{16,17}$

From the results of the above review, it can be seen that neurotization of free flaps appears to result in excellent motor and sensory outcomes for abdominal wall reconstruction, and thus suggests that abdominal wall allografts for "end-stage hernias" may be successful. The results also beg the question as to whether osseous fixation of abdominal wall free flaps and allografts should be performed. In cadaveric studies performed by Singh et al the abdominal wall allograft was designed as an osteomyocutaneous graft with ribs harvested contiguously. ${ }^{16}$ Chalfoun et al reported osseous fixation of their free flaps for abdominal wall reconstruction to the pubis, which is another possible addition to allograft design. ${ }^{5}$ Minimizing ischemic time of the abdominal wall allografts is important to the feasibility of the operation. ${ }^{18}$ Recipient vessels in abdominal wall transplantation have almost exclusively been the inferior epigastric, common iliac, or circumflex iliac vessels. ${ }^{19}$ It can be seen from the above review that the gastroepiploic vessels may be a convenient and expedient alternative that has been used in free flap abdominal wall reconstruction successfully. 


\section{Conclusion}

While innervated free flaps have been used in facial reanimation, phalloplasty, extremity reconstruction, and decubitus ulcer reconstruction, only nine published case series exist describing innervated free flap abdominal wall reconstruction. A majority of neurotized free flap reconstructions for abdominal wall defects have been performed for motor innervation, which is almost invariably successful. The addition of sensory innervation to free flap reconstruction of the abdominal wall would more completely satisfy the "like for like" principle of reconstructive surgery. The methods utilized in neurotized abdominal wall reconstruction should be applied to composite tissue allotransplantation of the abdominal wall to improve functionality, outcomes, and applicability.

Funding

None.

\section{Conflict of Interest}

None.

\section{References}

1 Ramirez OM, Ruas E, Dellon AL. “Components separation” method for closure of abdominal-wall defects: an anatomic and clinical study. Plast Reconstr Surg 1990;86(03):519-526

2 Koshima I, Soeda S, Yamasaki M, Kyou J. The free or pedicled anteromedial thigh flap. Ann Plast Surg 1988;21(05):480-485

3 Williams JK, Carlson GW, Howell RL, Wagner JD, Nahai F, Coleman JJ. The tensor fascia lata free flap in abdominal-wall reconstruction. J Reconstr Microsurg 1997;13(02):83-90

4 O'Hare PM, Leonard AG, Brennen MD. Experience with the tensor fasciae latae free flap. Br J Plast Surg 1983;36(01):98-104

5 Chalfoun CT, McConnell MP, Wirth GA, Brenner KA, Evans GR, Kobayashi M. Free tensor fasciae latae flap for abdominal wall reconstruction: overview and new innovation. J Reconstr Microsurg 2012;28(03):211-219

6 Penington AJ, Theile DR, MacLeod AM, Morrison WA. Free tensor fasciae latae flap reconstruction of defects of the chest and abdominal wall: selection of recipient vessels. Scand J Plast Reconstr Surg Hand Surg 1996;30(04):299-305

7 Ninković M, Kronberger P, Harpf C, Rumer A, Anderl H. Free innervated latissimus dorsi muscle flap for reconstruction of full-thickness abdominal wall defects. Plast Reconstr Surg 1998;101(04):971-978

8 Chevray PM, Singh NK. Abdominal wall reconstruction with the free tensor fascia lata musculofasciocutaneous flap using intra- peritoneal gastroepiploic recipient vessels. Ann Plast Surg 2003; 51(01):97-102

9 Harii K, Omori S. Use of the gastroepiploic vessels as recipient or donor vessels in the free transfer of composite flaps by microvascular anastomoses. Plast Reconstr Surg 1973;52(05):541-548

10 Hahn E Jr, Lee ES, Keith JD. A neurotized anterolateral thigh flap with a unique anastomosis to the gastroepiploic artery: a case report of a reconstruction of composite abdominal wall defect. Eplasty 2016;16:ic29

11 Wong CH, Lin CH, Fu B, Fang JF. Reconstruction of complex abdominal wall defects with free flaps: indications and clinical outcome. Plast Reconstr Surg 2009;124(02):500-509

12 Blondeel N, Boeckx WD, Vanderstraeten GG, et al. The fate of the oblique abdominal muscles after free TRAM flap surgery. Br J Plast Surg 1997;50(05):315-321

13 Koshima I, Nanba Y, Tutsui T, Takahashi Y, Itoh S, Kobayashi R. Dynamic reconstruction of large abdominal defects using a free rectus femoris musculocutaneous flap with normal motor function. Ann Plast Surg 2003;50(04):420-424

14 Iida T, Mihara M, Narushima M, et al. Dynamic reconstruction of full-thickness abdominal wall defects using free innervated vastus lateralis muscle flap combined with free anterolateral thigh flap. Ann Plast Surg 2013;70(03):331-334

15 Selvaggi G, Levi DM, Kato T, et al. Expanded use of transplantation techniques: abdominal wall transplantation and intestinal autotransplantation. Transplant Proc 2004;36(05):1561-1563

16 Broyles JM, Berli J, Tuffaha SH, et al. Functional abdominal wall reconstruction using an innervated abdominal wall vascularized composite tissue allograft: a cadaveric study and review of the literature. J Reconstr Microsurg 2015;31(01):39-44

17 Singh DP, Mavrophilipos VD, Zapora JA, et al. Novel technique for innervated abdominal wall vascularized composite allotransplantation: a separation of components approach. Eplasty 2014; $14: \mathrm{e} 34$

18 Giele H, Bendon C, Reddy S, et al. Remote revascularization of abdominal wall transplants using the forearm. Am J Transplant 2014;14(06):1410-1416

19 Giele H, Vaidya A, Reddy S, Vrakas G, Friend P. Current state of abdominal wall transplantation. Curr Opin Organ Transplant 2016;21(02):159-164

20 Sasaki K, Nozaki M, Nakazawa H, Kikuchi Y, Huang T. Reconstruction of a large abdominal wall defect using combined free tensor fasciae latae musculocutaneous flap and anterolateral thigh flap. Plast Reconstr Surg 1998;102(06):2244-2252

21 Koshima I, Moriguchi T, Inagawa K, Urushibara K. Dynamic reconstruction of the abdominal wall using a reinnervated free rectus femoris muscle transfer. Ann Plast Surg 1999;43(02): 199-203

22 Malheiro H, Ferreira A, Reis J, Choupina M, Ferreira A, Amarante J. Repair of a full-thickness abdominal wall defect with an innervated latissimus dorsi free flap. Scand J Plast Reconstr Surg Hand Surg 2007;41(03):146-148 